\title{
Study on the Internal Logic of Green Development and Persistence and Improvement of Ecological Civilization System
}

\author{
Xiangmin Xu , Wenshuang Zheng* \\ Sichuan Agricultural University, Sichuan 111306 , China.
}

Abstract:The purpose of the concept of green development is to accelerate the construction of my country's socialist ecological civilization, and promote a green cycle to achieve the goal of long-term green development. We must have a deeper understanding of the concept of green development so that we can better implement it and avoid inaction. The concept of green development can play a guiding role in the construction of ecological civilization and has certain research and implementation value. The concept of green development plays an indispensable leading role in the construction of ecological civilization.In order to further implement green development, we need to let more companies and individuals understand the concept of green development. Only by enabling more companies and individuals to understand this concept can it be possible to start from ourselves and carry the mission of green development ${ }^{[1]}$.

Keyword: Green Development, Ecological Civilization, Internal Logic

\section{Introduction}

The green development concept takes ecological civilization as its value orientation, sets long-term green development as the main goal, and transforms the social economy into a green economy. Through continuous research and development of new green technologies, we support the rapid development of green industries, minimize the damage to the ecological environment, and promote economic development and ecological civilization construction to reach a balanced state and develop together and harmoniously. There is a big difference between the ways of green development and economic development. Green development pays more attention to the balance of economy, society and ecological civilization environment, and harmonious and mutual assistance. In contrast to the current social environment, the improvement of social productivity and the excess production of enterprises, human beings' demands for resources and environment exceed the carrying capacity of nature. The emergence of the green development concept is the general trend of social development. In the context of the continuous deterioration of the ecological environment and the lack of resources, the emergence of the green development concept is an inevitable historical development.Integrate ecological civilization construction into economic construction.

My country's promotion of green development is still in its infancy, lacking certain practical experience, the public's awareness of green environmental protection is not enough, and the company's awareness of green development awareness is not clear enough, and it is temporarily unable to actively choose green development ${ }^{[3]}$. In addition, The relevant policies for green development are not perfect enough to provide effective legal protection and other issues. The specific performance is shown in Table 1 below:

The green awareness of relevant enterprises is weak and they have not actively implemented green production. If the company does not save resources, save energy and reduce emissions, it may have a negative impact on the ecological environment during the production process and cannot achieve green development. my country's implementation of the green development model was originally later than some Western countries. Some companies are limited by the traditional development model and dare not easily try the green development model.Green development is also beneficial to the enterprise itself, and because of the weak green awareness of the enterprise, it is unable to actively promote green production ${ }^{[4]}$.

The company lacks green marketing awareness and methods. Green marketing means that the company chooses pollution-free raw materials throughout the process, sells green products, forms a green market, and achieves the ultimate goal of green recycling. However, as far as the current general environment is concerned, many Chinese enterprises are not aware of the importance of green recycling due to the influence of traditional concepts or limited exposure to new concepts. Most companies may pay more attention to immediate benefits, but fail to consider that such short-sighted behavior is not conducive to environmental protection and harms the long-term interests of society.

The limited innovation ability or weak initiative consciousness of enterprises also increases the difficulty of green technology

Copyright (C) 2020 Xiangmin Xu et al.

doi: $10.18282 / 1-e . v 9 i 4.1686$

This is an open-access article distributed under the terms of the Creative Commons Attribution Non-Commercial License (http://creativecommons.org/licenses/by-nc/4.0/), which permits unrestricted non-commercial use, distribution, and reproduction in any medium, provided the original work is properly cited. 
Table 1. Difficulties facing green development

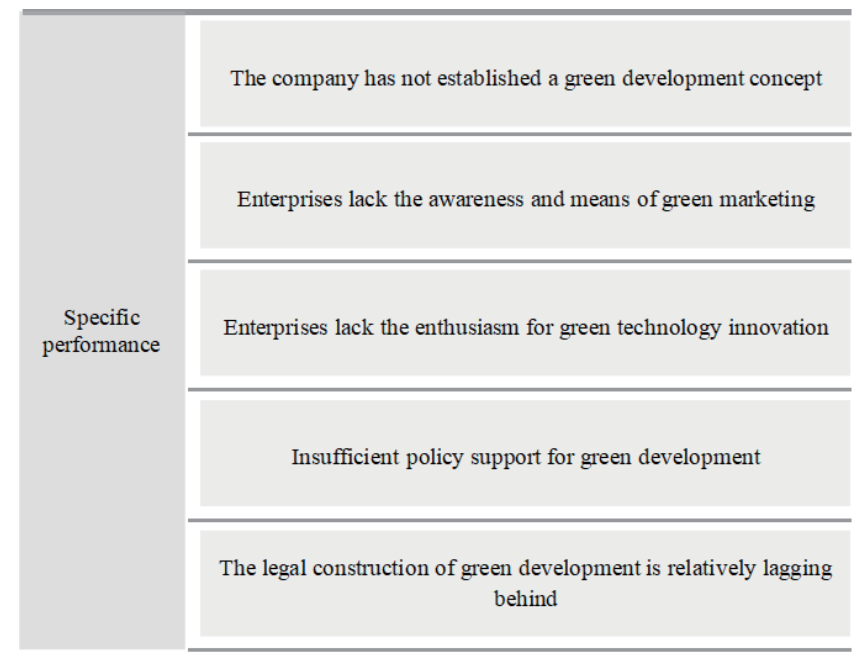

innovation. In particular, some traditional enterprises in our country are seriously backward in technology and equipment, and input and output are not proportional. If this continues, it will lead to waste of resources and is not conducive to economic development. Some companies may have sufficient R\&D capabilities, but due to the greater pressure of green technology innovation, the demand for funds and the risk of failure are high, capable companies are reluctant to try to innovate green technologies ${ }^{[5]}$. In the current market, the green products produced by enterprises have no obvious advantages over traditional products, and the lack of market competitiveness also makes enterprises mistakenly believe that green products are not popular with consumers. Therefore, this is not conducive to the promotion of green products in the market. At the same time, there is a shortage of talents for green technology innovation in enterprises, and the inability to overcome technical barriers in the industry has led to stagnatio

(4) Policy support for green development is weak, and relevant policy formulations are not perfect. However, my country's existing green policies are not perfect, for example: green development tax policy is not perfect. On the whole, my country's tax incentives for green products are not large, and there are few types, and the supervision mechanism is not mature enough, and the relevant supervision and tracking system is lacking. This gives some enterprises the opportunity to tax evasion and cannot save resources and protect the environment. The ultimate goal. The research and development of green technology requires a lot of money ${ }^{[6]}$. Regarding my country's immature investment mechanism for green technology innovation, it may have a negative impact on the enthusiasm of enterprises in research and development, and it cannot guarantee the long-term green technology innovation of enterprises. In the process of green technology innovation, enterprises may encounter many problems such as the break of the capital chain, which affects the progress of research and development or causes research and development to fail.

\section{Countermeasures to promote green development}

Green development involves many social organizations and individuals such as governments, enterprises, individuals, etc. If you want to smoothly advance the process, Then we must eliminate the resistance on the road of green development, find the problems in its process, and propose specific solutions to it.

Table 2 Specific strategies for implementing green development

\begin{tabular}{|l|l|}
\hline $\begin{array}{l}\text { Enhancing the green development concept } \\
\text { of business managers }\end{array}$ & $\begin{array}{l}\text { We must strengthen the green education of business managers and make } \\
\text { it change in consciousness, so that it can take the initiative to achieve green } \\
\text { development. Business managers need to recognize the social responsibilities } \\
\text { that companies should bear on the road of green development, and combine } \\
\text { the construction of ecological civilization with the company, and integrate this } \\
\text { culture into the entire process of business operations. }\end{array}$ \\
\hline Implement green marketing strategies & $\begin{array}{l}\text { The green management of an enterprise is to reform the existing policies of } \\
\text { the enterprise. We can summarize the green management system as the "5R" } \\
\text { principle: Research: Comprehensive consideration when making decisions, } \\
\text { pay attention to the construction of ecological civilization, and consider the } \\
\text { awareness of green environmental protection; Reduce): Energy saving and } \\
\text { emission reduction, try to choose no environmental protection Hazardous raw } \\
\text { materials, decompose the waste discharged from it, and it is best to reuse it; } \\
\text { Recycle effectively recycles used waste products or raw materials to minimize } \\
\text { its harm to the environment and achieve the goal of green development } \\
; \text { Rediscover: Convert ordinary products into new green products, increase R\&D } \\
\text { and capital investment in green products, so that it has outstanding advantages } \\
\text { and is more conducive to market promotion; Reserve: Improve the overall } \\
\text { masses Encourage employees to build an ecological civilization together. }\end{array}$ \\
\hline
\end{tabular}




\title{
Research on countermeasures and suggestions of Intangible Cultural Heritage Inheritance "entering campus"
}

\author{
Yanbing Yin, Chen Liu* \\ School of Economics and Management TianGong University, Tianjin 300384, China.
}

Abstract: Aiming at the problems that the current education practice of intangible cultural heritage is not fully implemented, and the campus curriculum system of intangible cultural heritage is not perfect, this paper puts forward some relevant policy suggestions, such as the construction of intangible cultural heritage education inheritance system, modular curriculum design, building resource collaboration platform and so on. It strengthens the important role of campus in the inheritance and protection of intangible cultural heritage, and provides a good scientific development system for the inheritance and protection of intangible cultural heritage in the campus channel

Keywords: intangible cultural heritage; educational inheritance; resource collaboration platform

As the essence of Chinese traditional culture, intangible cultural heritage (referred to as intangible cultural heritage) is not only the inheritance of skills, but also the continuation of its cultural connotation. Its inheritance and development is of great significance to the in-depth excavation of Chinese excellent traditional culture and the cultivation of national self-confidence. Promoting the intangible cultural heritage into the campus not only provides a new idea for the protection and inheritance of intangible cultural heritage, but also provides a beneficial attempt to improve the cultural and artistic cultivation of teachers and students and build a high-level quality education platform.

At present, the practice of intangible cultural heritage education in China is still in the exploratory stage, and there is a lack of mature curriculum system and promotion mode. Therefore, it is necessary to construct the curriculum system of intangible cultural heritage education inheritance and explore the education mode of intangible cultural heritage into campus on the basis of exploring the advantages of intangible cultural heritage education inheritance resources. It is urgent to strengthen policy support and focus

Copyright (C) 2020 Yanbing Yin et al.

doi: $10.18282 / 1-$ e.v9i4.1687

This is an open-access article distributed under the terms of the Creative Commons Attribution Non-Commercial License (http://creativecommons.org/licenses/by-nc/4.0/), which permits unrestricted non-commercial use, distribution, and reproduction in any medium, provided the original work is properly cited.

\begin{tabular}{|l|l|}
\hline Increase capital investment & $\begin{array}{l}\text { Green technology can solve many problems such as low resource utilization, } \\
\text { serious environmental pollution, and high corporate scrap rate. If green } \\
\text { technology can be used, the problems of human resource shortage and energy } \\
\text { shortage can be solved, and environmental pollution can be prevented and } \\
\text { controlle }\end{array}$ \\
\hline $\begin{array}{l}\text { Strengthen and improve policy support for } \\
\text { green development }\end{array}$ & $\begin{array}{l}\text { Corresponding taxation and fiscal policies should be improved, and green } \\
\text { product enterprises should be given certain green preferences and enjoy tax } \\
\text { benefits. At present, my country should establish a sound energy taxation } \\
\text { mechanism and strengthen control over the use of non-renewable resources } \\
\text { such as fossil fuels. }\end{array}$ \\
\hline
\end{tabular}

\section{Conclusion}

Building green development and improving the system of ecological civilization are complementary. Green development is both a prerequisite for achieving ecological civilization and a sufficient condition for achieving ecological civilization. In summary, we have discovered the dilemmas faced by green development in today's social environment, and further analyzed, put forward the countermeasures and methods for implementing green development under the premise of ensuring ecological civilization. On the one hand, we should strengthen the publicity of green development and increase the public's or enterprises' awareness of it; on the other hand, the government needs to expand capital investment and implement multiple channels to promote the construction of ecological civilization and strengthen citizens' green awareness.

\section{References}

[1]Morrison R S. Building an Ecological Civilization[R]. Manchester:Social Anarchism: A Journal of Theory\&Practice, 2007. [2]Shimada K, Tanaka Y, Gomi K, et al. Developing a long-term local society design methodology towards a low-carbon economy: Anapplication to Shiga Prefecture in Japan [J]. Energy Policy, 2007,35(9): 4688-4703. 